\title{
Rectangular Patch with Parasitic Folded Dipoles: A Reconfigurable Antenna
}

\author{
${ }^{\#}$ Elyas Palantei ${ }^{1}$, David V. Thiel ${ }^{2}$, and Steven G. O'Keefe ${ }^{2}$ \\ ${ }^{1}$ CWMA Griffith University and Electrical Engineering Department, Hasanuddin University \\ 170 Kessels Road, Nathan, Brisbane, Q4111, Australia, e.palantei@,griffith.edu.au \\ J1. Perintis Kemerdekaan Km.10 Tamalanrea Makassar Indonesia, elyas palantei@unhas.ac.id, \\ ${ }^{2}$ Centre for Wireless Monitoring \& Applications (CWMA), Griffith School of Engineering, \\ Griffith University, Brisbane, Australia, d.thiel@,griffith.edu.au, s.okeefe $@$,griffith.edu.au>
}

\section{Introduction}

There is an increasing demand for multifunctional wireless communication devices, such as handsets, PDAs, and laptop computers. Desirable features of such products include low cost, light weight, long battery life, small/compact design and user-friendly operation. The antenna in these devices must be integrated with the operational electronics. These antennas must either be multiband or should have the capability to be reconfigured. Such dynamic changes might include the frequency of operation or the direction of the main radiation lobe. Such changes can be controlled, dynamically and autonomously, to maintain antenna performance during all operation conditions.

One possible reconfigurable antenna type consists of a number of parasitic structures where the current is controlled electronically using RF control circuits such as microwave p.i.n. diodes, varactor diodes, MEMs switches, and GaAs FET switches [1]. This control can be used to change the operational frequency and the radiation pattern [2].

In this paper, the tuning and steering of a rectangular patch antenna is controlled by switching the patch and folded dipoles configuration. This reconfigurable antenna is controlled by the changing the voltage across a number of p.i.n. diodes in the parasitic elements. This antenna with the associated RF control unit [3-4] forms a reconfigurable antenna which provides one solution to a number of communications problems [5-6].

\section{Antenna Structure and Modelling}

\subsection{Antenna Structure}

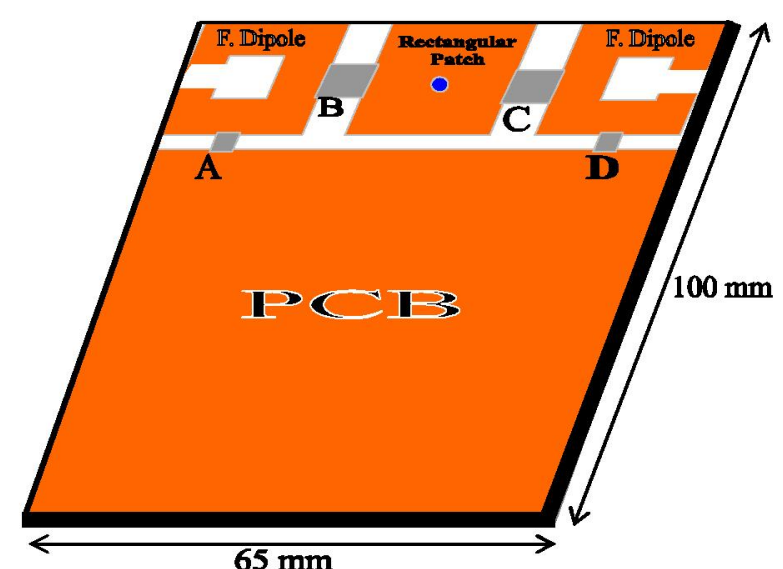

(a)

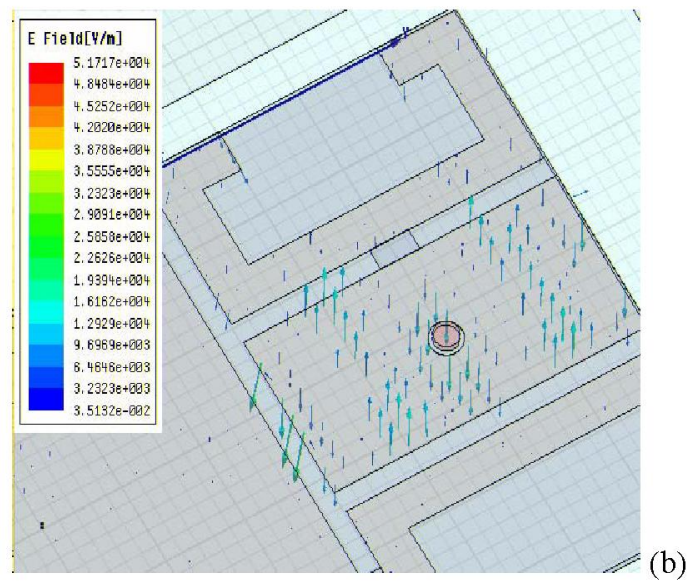

Fig. 1: The reconfigurable antenna: (a) rectangular patch antenna with parasitic folded dipoles (b).E-field distribution of antenna structure modelled using FEM algorithm

The antenna consists of single rectangular patch at the centre and two stripline folded dipoles positioned at two edges, right and left sides above a ground plane (see Fig.1). The patch is fed via a conducting probe protruding through the dielectric substrate. The two folded dipoles have two p.i.n. diode switches (labelled A, B, C, and D in Fig. 1 (a)) which can be switched into one of four conditions, shorted or un-shorted to ground and connected or disconnected to the active patch. 
These diodes form part of the switching circuit located on the bottom side of the ground plane underneath the radiating elements. A ground plane of $65 \times 100 \mathrm{~mm}$ dimension is located underneath the dielectric layer in addition to a ground plane on the top surface representing the receiver electronics. Table 1 lists the material properties used in simulation.

Shorting one dipole to ground via A directs the pattern to a direction away from A. Connecting the other dipole to the active patch via $\mathrm{C}$ changes the antenna frequency because the effective area of the driven layer is enlarged. Both folded dipoles can also be set in "open circuit configuration" (un-shorted to ground and disconnected to patch) so only the rectangular patch itself is active. The effect of these configurations is shown in Figs. 1.(a), 2, 3 and 4

Table-1: The structure and dimension of reconfigurable patch antenna with parasitic folded dipole

\begin{tabular}{||l|c|c|c|c||}
\hline \multirow{2}{*}{ Structures } & \multicolumn{3}{c||}{ Antenna Dimension } \\
\cline { 2 - 5 } & Thickness (mm) & Width (mm) & Length(mm) & Radius(mm) \\
\hline $\begin{array}{l}\text { Dielectric material: Roger RT/ Duroid 5880 } \\
\text { (tm), Relative Permitivity. =2.2 }\end{array}$ & 0.5 & 65 & 100 & - \\
\hline Conducting wire: Copper, Rel. Permit =1 & 0.5 & - & - & 1.5 \\
\hline PCB track (PEC) & 0.05 & 65 & 57.5 & - \\
\hline Rectangular patch (PEC) & 0.05 & 20 & 40 & - \\
\hline Folded dipoles (PEC) & 0.05 & 20 & 40 & - \\
\hline Ground plane (PEC) & 0.05 & 65 & 100 & - \\
\hline
\end{tabular}

Table 2: Antenna switching configurations

\begin{tabular}{|c|c|c|c|c|c|}
\hline \multicolumn{4}{|c|}{ Switching Configurations } & \multirow{2}{*}{$\begin{array}{c}\mathrm{f}_{\mathrm{o}} \\
(\mathrm{GHz})\end{array}$} & \multirow{2}{*}{$\begin{array}{l}\text { Main Beam } \\
\text { Direction }\left(^{0}\right)\end{array}$} \\
\hline p.i.n. diode $\mathrm{A}$ & p.i.n. diode $B$ & p.i.n. diode $\mathrm{C}$ & p.i.n. diode $\mathrm{D}$ & & \\
\hline Off & Off & Off & Off & $10 / 11$ & $0 / 180$ \\
\hline Off & On & Off & On & $5 / 15$ & $45 / 225$ \\
\hline On & Off & On & Off & $5 / 15$ & $315 / 135$ \\
\hline Off & On & On & Off & $14 / 15$ & $345 / 165$ \\
\hline
\end{tabular}

All possible switching configurations are listed in Table 2. The p.i.n. diodes operate at two distinct states, "On" or "Off" respectively, which correspond to logic levels from a microcontroller. These logic levels are determined by the control algorithm which receives inputs form the RF circuitry. In practice, the logic voltage levels vary depending on the type of controller used. The work reported in [3-4] using the PIC16F62x chip controller noted that the high logic level was greater than 4 Volts when the generated power supply is approximately 4.9 Volts and the low logic level was less than 0.5 Volts. If the controller chip CC1010 is used, then the low logic level is approximately 0 Volt and the high logic level is approximately $\mathrm{V}_{\mathrm{cc}}+0.3$ Volts (where, $\mathrm{V}_{\mathrm{cc}}$ is the supply voltage). $\mathrm{V}_{\mathrm{cc}}$ can be typically set in the range $2.7-3.6$ Volts. The generation of proper biasing is a crucial step because it determines the residual impedance of p.i.n. diodes and so the effectiveness of the switch [4].

\subsection{Numerical Modelling}

This antenna was designed to work at $5 \mathrm{GHz}$ to suit the next-G of WiMAX mobile terminals. It was modelling using FEM utilising the HFSS software [7]. The modelling results showed operation bands at 10 and $15 \mathrm{GHz}$. Fig. 1 (b) shows the E-field distribution across the active structure at $5 \mathrm{GHz}$. This shows that the antenna is predominantly linearly polarised as the E-field pattern is predominantly parallel to the antenna axis.

While most patch antennas have narrow bandwidths, this patch with folded dipoles has a larger bandwidth. The structure dimensions were optimized to ensure the antenna operatures successfully in the desired frequency bands. In the model, the p.i.n. diode was represented by a perfect conductor for "ON" states and an open circuit for "OFF" states [8].

The various switch conditions have a significant effect on the current surface distribution across the antenna (see Fig.2). In Fig.2 (a), the surface current $J_{\text {surf }}$ distribution is concentrated on the rectangular patch with little current on the folded dipoles. In this case, the Jsurf variation is from zero to a maximum $1.936 \times 10^{2}(\mathrm{~A} / \mathrm{m})$. For the switching condition shown in Fig.2 (b) the $J$ surf is significant on the left dipole. Overall, at the active conducting antenna elements (rectangular patch 
and folded dipole), the current variation varies from zero to a maximum of $1.5647 \times 10^{2}(\mathrm{~A} / \mathrm{m})$. When both dipoles are connected to active patch (Fig2.(c)) then the currents are significant in both dipoles.

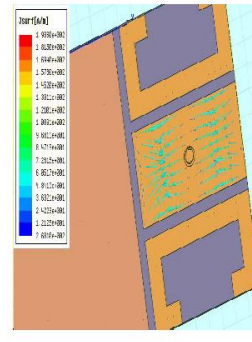

(a)

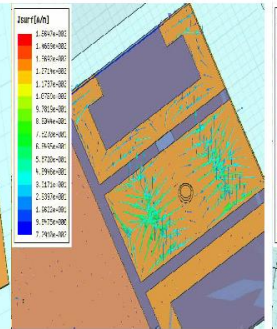

(b)

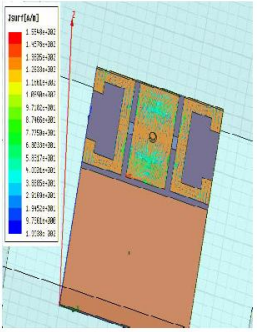

(c)

Fig.2: The current surface vectors $\left(J_{s u r f-A} / \mathrm{m}\right)$ of the conducting layers, i.e. rectangular patch and folded dipoles for 3 different configurations: (a) both folded dipoles "isolated", (b) the right side dipole was shortcircuited to ground and the left one connected to active patch, (c) both dipoles connected to active patch.

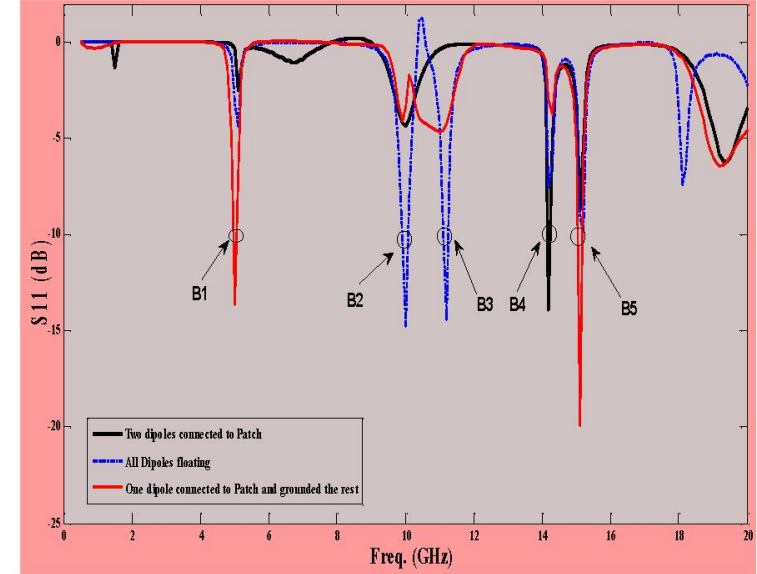

Fig.3: The $\mathrm{S}_{11}$ of reconfigurable antenna.

The return loss $\left(S_{11}\right)$ of reconfigurable patch antenna for 3 different switching states is illustrated in Fig. 3 assuming a transmission line feed impedance of $50 \mathrm{ohms}$. A change in the switching condition affects the operating band of the antenna. With one folded dipole connected to the active patch while the dipole is shorted to ground, the antenna is tuned to both 5 and $15 \mathrm{GHz}$. However, when both folded dipoles are isolated by their two switches, the frequency tuning changes to 10 and $11 \mathrm{GHz}$. When both dipoles are connected to the patch, the only resonant frequency is 15 $\mathrm{GHz}$. The impedance bandwidth of each reconfigured element structures varies from more than 100 $\mathrm{MHz}$ to $250 \mathrm{MHz}$.

The effect of switching contributes to the deflection of beam pattern direction by approximately $45^{\circ}$ in the right or left directions (see Fig.4 (a)-(c)) depending on which dipole is shorted to ground. Meanwhile, if both folded dipoles are connected to the active patch element then the main beam is deflected by $15^{\circ}$ as shown in Fig.4.(d)

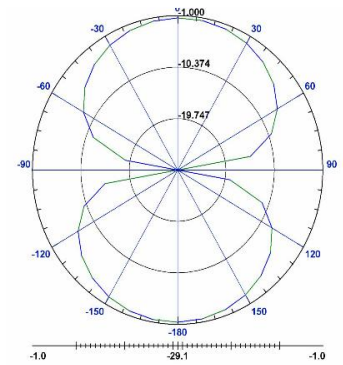

(a)

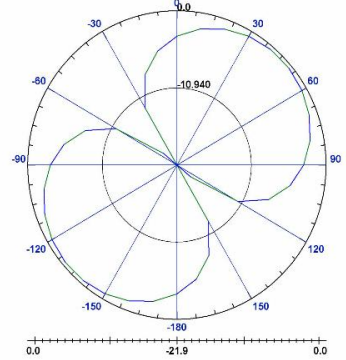

(b)

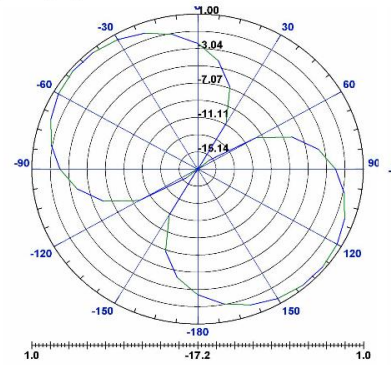

(c)

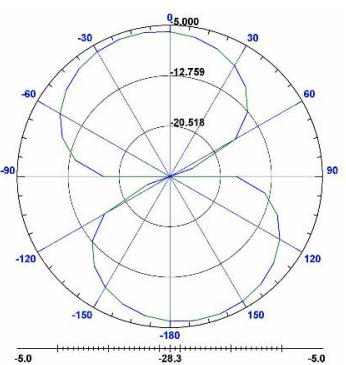

(d)

Fig. 4: The beam pattern of the reconfigurable antenna for four switching conditions on the azimuthal plane $\left(\theta=0^{\circ}\right)$ : (a) all folded dipoles are in "floating condition" at $10 \mathrm{GHz}$ band, (b)-(c) one folded dipole connected to active patch and the rest (right or left) short circuited to ground at 5 or $15 \mathrm{GHz}$ bands, (d) all dipoles connected to patch and un-shorted to ground at $15 \mathrm{GHz}$ band.

\section{Typical Application}

The antenna is suitable for the base station terminal tracking in WiMAX networks. Consider the network coverage of two terminals as illustrated in Fig.5(a). If there are $\mathrm{N}$ active customers at a certain time and the handset of customer 2 employs the reconfigurable antenna (for example as required by multifunctional services such as sms, video or moving picture down loading, voice, and internet), the antenna will execute the algorithm illustrated in Fig.5 (b). Initially, the antenna handset will point to the first detected base station; suppose this is station A. If the device finds no line available, all bands $B_{1}=5 \mathrm{GHz}, B_{2}=10 \mathrm{GHz}$ and $B_{3}=15 \mathrm{GHz}$ are fully occupied, then the RF controller unit instructs a change to the antenna pattern direction. When the handset 
captures the signal then one line will be occupied immediately to establish the communication in the network.
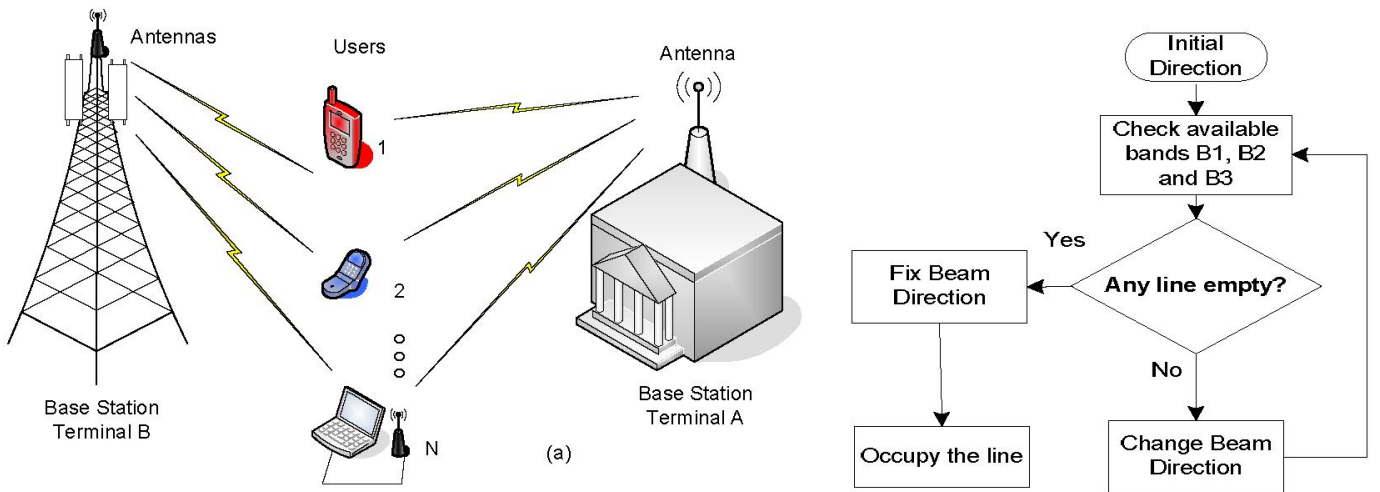

Fig. 5: An application of constructed-reconfigurable antenna: (a) WiMAX network, (b) operation algorithm

The patch with parasitic folded dipoles forms an integrated, single port, antenna structure with a number of advantages. These include, boosting the performance of WiMAX network terminals such as laptops, PDAs, and handsets. The multifunctional and steerable pattern capabilities of the antenna device allow the flexible and reliable communication access in the network because the more bandwidth available and more compact and intelligent devices can be used. In future, the typical WiMAX services can reach the coverage with the radius more than $20 \mathrm{~km}$ depending on the frequency operation [9].

\section{Conclusion}

A patch with folded dipole antenna elements was found to be an effective reconfigurable antenna. This antenna allows for three bands operation such as $5 \mathrm{GHz}, 10 \mathrm{GHz}$ and $15 \mathrm{GHz}$, as required for WiMAX applications. The antenna must be supported by an RF control unit as an integrated part of the transceiver circuitry to maintain the appropriate direction and frequency of operation.

\section{References}

[1] N. Behdad and K. Sarabandi, "Dual-Band Reconfigurable Antenna with a Very Wide Tunability Range," IEEE Transactions on Antennas and Propagation, Vol. 54, No.2, February 2006, pp.409-416.

[2] A.C.K. Mak, C.R. Rowell, R.D. Murch, and C-L. Mak, "Reconfigurable Multiband Antenna Designs for Wireless Communication Devices," IEEE APS Transactions, Vol.55, No.7, July 2007; pp.1919-1928.

[3] E. Palantei and D.V. Thiel. "Symmetry Problems in Switched Parasitic Smart Antennas" on the IEEE APS International Symposium, , 10 -15 June 2007, Honolulu, HI, USA.

[4] E. Palantei and D.V. Thiel, "The Impact of Bias Voltage on the Performance of a P.I.N. Diode Loaded Smart Antenna." Journal of the Japan Society of Applied Electromagnetics and Mechanics (JSAEM), Vol.15, No.3, pp.274-277, Sept, 2007.

[5] C.G. Christodoulou, D.A. Anagnostou, and V. Zachou, "Reconfigurable Multifunctional Antennas," Proceedings of IEEE APS Conference, 2006: pp.176-179.

[6] C.G. Christodoulou, D.A. Anagnostou, and L.M. Feldner, "Reconfigurable Antennas," Proceedings of IEEE International Workshop on Anti-Counterfeiting, Security \& Identification, 16-18 April 2007: pp.9-12.

[7] (2005) HFSS v9.3. Ansoft Corp. [Online]. Available:http://www.ansoft.com/

[8] H.Pan, J.T. Bernhard, and V.K. Nair, "Reconfigurable Single-Armed Square Spiral Microstrip Antenna Design," IEEE iWAT Conference, 2006; pp.180-183.

[9] T. Javornik, G. Kandus, A. Hrovat and I. Ozimek, "Comparison of WiMAX coverage at $450 \mathrm{MHz}$ and 3.5 GHz" On $7^{\text {th }}$ COST 290 Management Committee and Technical Meeting, September 29-30, 2006, Split. http://www.cost290.org/ 